\title{
Primum non nocere. The case for a critical approach to global mental health
}

\author{
P. Bracken ${ }^{1 *}$ J. Giller ${ }^{1}$ and D. Summerfield ${ }^{2}$ \\ ${ }^{1}$ Centre for Mental Health Care and Recovery, Bantry General Hospital, Bantry, Co Cork, Ireland \\ ${ }^{2}$ Institute of Psychiatry, Psychology \& Neuroscience, King's College, London, UK
}

\begin{abstract}
The Movement for Global Mental Health (MGMH) argues that there is a moral imperative that psychiatric treatments should be made available to all communities across the world. But psychiatric theories, categories and interventions emerged in the Western world are based on a set of assumptions about the nature of the self and society, nature and the supernatural, health and healing that are not universally accepted. In this paper we argue that there is a stronger moral case for caution with regard to the export of psychiatric thinking. Without a critical interrogation of such thinking the MGMH is at risk of doing a great deal of harm to the diverse, and sometimes fragile, systems of care that already exist across the world.
\end{abstract}

First published online 15 August 2016

Key words: Global mental health, critical thinking, epistemology, reductionism.

\section{Introduction}

An emergent Movement for Global Mental Health $(\mathrm{MGMH})$, supported by the World Health Organisation (WHO) and a range of other funding agencies, is lobbying for the global provision of 'evidence-based' psychiatric and psychological treatments as a moral imperative (Patel et al. 2011). Its proponents have made ambitious claims intended to 'sell' the MGMH but these are running well ahead of the facts on the ground (Summerfield, 2008) and attempts to raise debate about the assumptions on which the movement is based have been summarily dismissed. For example, Vikram Patel, one of the leaders of the $\mathrm{MGMH}$, has attacked such critiques as reminiscent of 'the most virulent brand of cultural relativism, which smacks not only of ignorance of a vast body of scientific evidence but more disturbingly of the racist ideologies that led one-time colonial administrators to deny mental health care to the 'natives' because they were either perceived to be psychologically immature or had supernatural treatments to deal with their conditions' (Patel, 2014). Such astonishing comments ignore the fact that the growing counter-discourse (Shukla et al. 2012; Clark, 2014; Fernando, 2014; Mills, 2014; White \& Sashidharan, 2014) is serious, evidence-based and contains many 'native' voices. In this paper we will argue that there is, in fact, a far stronger moral case for caution when it comes to the transfer of Western psychiatric theories, categories and interventions to non-Western settings, with their diverse histories,

\footnotetext{
* Address for correspondence: P. Bracken, Centre for Mental Health Care and Recovery, Bantry General Hospital, Bantry, Co Cork, Ireland. (Email: patjbracken@gmail.com)
}

cultural traditions, definitions of the person, economic imperatives and modes of help-seeking.

The dominant paradigm in psychiatry, and that upon which the MGMH is predicated, is technological (Bracken et al. 2012). Through the lens of this paradigm, which had its origins in the European asylums of the 19th century (Porter, 2002), mental health problems show up as technical challenges that demand a scientific response. The priorities are to classify accurately, identify universal causal factors and pathways, and to seek efficient forms of intervention. In this formulation, progress is understood to come from scientific researchers and treatments (whether pharmacological or cognitive/behavioural) delivered by trained professionals. The non-technical aspects of care (values, meanings and relationships) are of secondary concern.

This paradigm, however, is based on a set of ontological, epistemological and empirical/therapeutic assumptions that are historically and culturally contingent. We shall define these in turn, show how they shape the claims made for the field, and identify serious challenges to each.

\section{Ontological assumptions}

Modern psychiatry understands mental health problems as arising from faulty mechanisms or processes in the brain, or the mind, of an individual. It asserts the ontological equivalence of mental and physical illnesses. The WHO endorses this position, and consistently brackets 'mental, neurological and substance-use disorders' together, arguing that ' $[t]$ he absence of cures, and the dearth of preventive interventions for such disorders in part reflects a limited understanding of the brain and its molecular and cellular mechanisms' 
(Collins et al. 2011). The Research Domain Criteria approach, supported by the US National Institute of Mental Health (NIMH), simply accepts that 'mental disorders can be addressed as disorders of brain circuits' (Insel et al. 2010).

However, this position is based on a profound, but unsubstantiated, assumption: that the mental world of human beings can be understood as simply a product of brain processes. This reductionist ontology is contested both philosophically and scientifically within the Western world, from which it originated (Kirmayer \& Gold, 2012), and where voices of service users are increasingly challenging the hegemony of such explanations (Stastny \& Lehmann, 2007). Moreover, in other cultural settings, 'mental suffering' is often conceptualised as involving spiritual and communal dimensions; something that cannot be understood using a Western ontology, with its primary focus on the individual and his/her 'brain processes'.

The cultural psychologist, Richard Schweder, describes how many people make sense of suffering by tracing 'its genesis to some 'order of reality' where one may point the finger at events and processes that can be held to be the cause' (Schweder, 2003). Anthropologists study such 'causal ontologies' to tease out the ways in which their explanatory power is entwined with ideas about culture and morality. And, as Kirmayer (2011) points out, 'these ontologies recognise different types of agency or influence as sources of healing efficacy'.

In effect, the MGMH is promoting the conversion of individuals in non-Western settings from traditional and culturally-orientated understandings of states of madness and distress to medico-psychiatric understandings. They are promoting a particular ontology as though it was simply the 'truth'. But, characterising a community's beliefs about suffering as erroneous, carries the risk of undermining the very ontology that can offer people a sense of meaning. Individuals in societies that have shed a religious or spiritual ontology may well be more vulnerable to mental breakdown characterised by a loss of meaning and hope (Bracken, 2002). Furthermore, there is evidence that the promotion of reductionist biological understandings of mental health problems can actually increase stigma and marginalisation (Angermeyer et al. 2011).

\section{Epistemological assumptions}

A second fundamental claim of the GMH lobby is that mental disorders can be understood by employing the same sort of quantitative scientific tools used to understand other global health issues. For example, in the literature of GMH 'depression' is characterised as a disease in the same way that malaria is, with an aetiology, a symptom picture, a course and a prognosis, with or without treatment. The assumption here is that human emotions and behaviours can be studied independent of context, the 'symptoms' identified are considered to be equally pathological wherever they are encountered. The MGMH states that a key objective is to refine understandings of where to draw the line between 'case' and 'normal', but they pay little regard to socio-cultural issues in this exercise. Patel et al. (2009) simply assert that 'the constellation of symptoms used to characterize depression can be identified in all countries'. In other words, the MGMH is using the template for disorders of mood developed by Western psychiatry as the means by which it examines distress in all the cultures of the world. But anthropological (Obeyesekere, 1985), sociological (Lewis, 2009) and even historical (Hacking, 1995) research makes it clear that our emotional worlds and what flows from these cannot be separated from the social context in which they arise. States of sadness and depression often relate to loss. As Jenkins \& Kleinman (1991) write: 'Culture organizes the experience and interpretation of loss, here as the sting of desperate grief, there as ambivalent silence, elsewhere as concatenations of feelings - guilt with sadness, rage with hopelessness, fear of sorcery with calm acceptance of fate - that hold special salience (and in some cases arguably may only be felt) in particular social systems'. Given this diversity, the claim by the WHO that 'depression' (assumed a unitary, universal pathological condition) is the number one or two most burdensome diseases in the world- more burdensome than AIDS, tuberculosis or cardiovascular disease - is virtually meaningless.

The specific challenges of interpretation that psychiatry faces, outlined by Karl Jaspers a 100 years ago (de Leon, 2014), are simply ignored by the MGMH. We maintain that, while quantitative, biomedically-framed methodologies have a place in the understanding of mental illness, if we are to do justice to the specific challenges that it poses, these must be secondary to a primary discourse focused on meanings and contexts, values and priorities, relationships and power (Bracken et al. 2012).

Knowledge and power are always related (Foucault, 1980). The knowledge that constitutes biomedical psychiatry is produced in Western-based, or Western-oriented, research centres and university departments, and this is the knowledge upon which the discourse of the MGMH is predicated. Asserting its primacy works to undermine systematically the value of local epistemologies.

\section{Empirical/therapeutic assumptions}

The MGMH pays lip service to local approaches to healing, but in practice sees them as an obstacle: 
'Poor knowledge and stigmatising beliefs among the general population were also identified as key barriers, reducing willingness to seek help' (Eaton et al. 2011). But the 'help' the MGMH offers is always derived from Western psychiatry. In a GMH paper on 'packages of care for depression', only three forms of intervention are taken to be 'evidence-based'. These are drug treatments, electroconvulsive therapy (ECT) and psychotherapy (either CBT or interpersonal psychotherapy) (Patel et al. 2009). In fact, the evidencebase for these treatments in Western societies reveals that most of their efficacy can be explained by 'non-technological' aspects. Two widely reported meta-analyses have demonstrated that the greatest therapeutic benefit of anti-depressant drugs in drug trials is due to the placebo effect (Kirsch et al. 2008; Fournier et al. 2010). The placebo effect is a complex phenomenon but essentially involves non-technical aspects of care, such as relationships and meanings (Moerman, 2002; Kirmayer, 2011). The placebo effect is also of substantial importance in explaining the benefits of ECT (Rasmussen, 2009; Read \& Bentall, 2010). Furthermore, meta-analyses of outcomes in psychotherapies indicate that the personality of the therapist and his/her relationship with the patient are of far greater importance than the particular technique that is being used (Cooper, 2008). Meanings and relationships are central to recovery from mental illness, including (what is termed) 'serious mental illness' (Repper \& Perkins, 2003).

In non-Western settings too, many non-psychiatric interventions work on the basis of generating hope and reducing demoralisation. Such interventions (religious, spiritual, traditional) can be powerfully effective (Fernando, 2014). In 2002, researchers from Bangalore studied a healing shrine in Tamil Nadu, India. They had interviewed everyone who attended over a 3-month period and found that many of them fulfilled Western criteria for serious mental illness (such as schizophrenia). However they found that most of these improved substantially without anti-psychotic or other medication. The authors note that: 'In addition to the specific healing power associated with the temple, the observed effects may have also resulted from the supportive, non-threatening, and reassuring setting. Healing temples thus may constitute a community resource for mentally ill people in cultures where they are recognised and valued' (Raguram et al. 2002).

WHO studies in the 1960s and 70s found substantially better outcomes for people with serious mental illness/schizophrenia in non-Western countries than in the West (Jablensky \& Sartorius, 2008). Some researchers have argued that the multiplicity of treatment and healing modalities in such settings may well contribute to better outcomes (Halliburton, 2004). But local ways of understanding and dealing positively with mental health problems can be easily undermined. Higgenbotham \& Marsella (1988) described the problematic uniformity of psychiatric care in the capital cities of Southeast Asia, despite large social, cultural and linguistic differences in these cities. This 'homogenization of psychiatry' had been the legacy of earlier generations of Western psychiatric experts, and had led to 'deleterious initial, secondary and tertiary after-shocks' within local cultural systems, as the diffusion of Western-based knowledge promoted professional elitism and asylum-based responses to distress regardless of context, with overuse of medication and ECT. Indigenous healing systems were undermined, to the detriment of those who had always turned to them.

More recently, Jain \& Jadhav (2009) highlighted similar issues in their study of a community mental health programme in North India, which made psychotropic medication available to people in rural communities. They write: 'As the pill journeys from the Ministry of Health to the clinic, its symbolic meaning transforms from an emphasis on accessibility and participation to the administration of a discrete 'treatment'. Instead of embodying access and participation, the pill achieves the opposite: silencing community voices, re-enforcing existing barriers to care and relying on pharmacological solutions for psychosocial problems'.

\section{Conclusion}

We do not question that important gains can be made through communication and collaboration between mental health workers (however defined) in different parts of the world. But the current movement to promote GMH is characterised by an almost evangelical belief in the benefits of psychiatry. We believe that much of this is irrelevant to the living predicaments of non-Western subjects. The stark reality for the vast majority of people in the non-Western world, transcending everything, is poverty. Currently one quarter of the global population lives in near destitution and 3.5 million children die of starvation annually. What is 'mental health' in this broken social world? (Summerfield, 2012). An approach to mental health that does not see contextual issues as primary and that promotes a reductionist understanding of mental illness has the potential to do a great deal of harm. Leaders of the MGMH assert that 'One of the unique aspects of global mental health is the extent of engagement with communities and acknowledgement of context in the design, implementation, valuation and uptake of research' (Patel, 2014). They also maintain 
that: 'Much of the driving force in global mental health is led by investigators and policy-makers based in developing countries'. We believe that there is little evidence to support these claims and contend that this movement simply pays lip service to local contexts and understandings. 'Investigators and policy-makers' are often those educated in Western spheres of knowledge. In a world that is fundamentally unequal, with power and wealth overwhelmingly in the hands of the West, any attempt to redress these inequalities has to be based on a profound respect for other traditions. We need an approach that takes critical thinking seriously, that is grounded in humility and an overarching desire to allow the voices from other cultural settings, particularly those of the most marginalised, to be heard and a willingness to learn from them. The current MGMH does not fulfil these requirements.

\section{Acknowledgements}

None.

\section{Financial support}

This research received no specific grant from any funding agency, commercial or not-for-profit sectors.

\section{Conflict of interests}

None.

\section{References}

Angermeyer MC, Holzinger A, Carta MG, Schomerus G (2011). Biogenetic explanations and public acceptance of mental illness: systematic review of population studies. British Journal of Psychiatry 199, 367-372.

Bracken P (2002). Trauma: Culture, Meaning and Philosophy. Whurr Publishers: London.

Bracken P, Thomas P, Timimi S, Asen E, Behr G, Beuster C, Bhunnoo S, Browne I, Chhina N, Double D, Downer S, Evans C, Fernando S, Garland MR, Hopkins W, Huws R, Johnson B, Martindale B, Middleton H, Moldavsky D, Moncrieff J, Mullins S, Nelki J, Pizzo M, Rodger J, Smyth M, Summerfield D, Wallace J, Yeomans D (2012). Psychiatry beyond the current paradigm. British Journal of Psychiatry 201, 430-434.

Clark J (2014). Medicalization of global health 2: the medicalization of global mental health. Global Health Action 7, 23998. doi: 10.3402/gha.v7.24000.

Collins PY, Patel V, Joestl SS, March D, Insel TR, Daar AS (2011). Grand challenges in global mental health. Nature $475,27-30$.
Cooper M (2008). Essential Research Findings in Counselling and Psychotherapy. Sage Publications: London.

de Leon J (2014). A post-DSM-III wake-up call to European psychiatry. Acta Psychiatrica Scandinavica 129, 76-77.

Eaton J, McCay L, Semrau M, Chatterjee S, Baingana F, Araya R, Ntulo C, Thornicroft G, Saxena S (2011). Scale up of services for mental health in low-income and middle-income countries. Lancet 378, 1592-1603.

Fernando S (2014). Mental Health Worldwide. Culture, Globalization and Development. Palgrave Macmillan: Basingstoke.

Foucault M (1980). Truth and power. In Power/Knowledge. Selected Interviews and Other Writings, 1972-1977 (ed. C Gordon), pp. 109-133. Harvester Wheatsheaf: New York.

Fournier JC, DeRubeis RJ, Hollon SD, Dimidjian S, Amsterdam JD, Shelton RC, Fawcett J (2010). Antidepressant drug effects and depression severity: a patient-level meta-analysis. JAMA Psychiatry 303, 47-53.

Hacking I (1995). Rewriting the Soul: Multiple Personality and the Sciences of Memory. Princeton University Press: Princeton.

Halliburton M (2004). Finding a fit: psychiatric pluralism in South India and its implications for WHO studies of mental disorder. Transcultural Psychiatry 41, 80-98.

Higgenbotham N, Marsella A (1988). International consultation and the homogenization of psychiatry in Southeast Asia. Social Science and Medicine 27, 553-561.

Insel T, Cuthbert B, Garvey M, Heinssen R, Pine DS, Quinn K, Sanislow C, Wang P (2010). Recovery Domain Criteria (RDoC): towards a new classification framework for research on mental disorders. American Journal of Psychiatry 167, 748-751.

Jablensky A, Sartorius N (2008). What did the WHO studies really find? Schizophrenia Bulletin 34, 253-255.

Jain S, Jadhav S (2009). Pills that swallow policy: clinical ethnography of a community mental health program in northern India. Transcultural Psychiatry 46, 60-85.

Jenkins J, Kleinman A (1991). Cross-cultural studies of depression. In Psychosocial Aspects of Depression (ed. J Becker and A Kleinman), pp. 67-99. Lawrence Erlbaum Associates: Mahwah, New Jersey.

Kirmayer L (2011). Unpacking the placebo response: insights from ethnographic studies of healing. Journal of Mind-Body Regulation 1, 112-124.

Kirmayer L, Gold I (2012). Re-socializing psychiatry: critical neuroscience and the limits of reductionism. In Critical Neuroscience: A Handbook of the Social and Cultural Contexts of Neuroscience (ed. S Choudhury and J Slaby), pp. 307-330. Wiley-Blackwell: Chichester.

Kirsch I, Deacon BJ, Huedo-Medina TB, Scoboria A, Moore TJ, Johnson BT (2008). Initial severity and antidepressant benefits: a meta-analysis of data submitted to the Food and Drug Administration. PLoS Medicine 5, e45. doi: 10.1371/ journal.pmed.0050045.

Lewis B (2009). Obsession: a history, and: the loss of sadness. How psychiatry transformed normal sorrow into depressive disorder, and: shyness: how normal behaviour became a sickness, and: bipolar expeditions: mania and depression in American culture (review). Literature and Medicine 28, 152-171. 
Mills C (2014). Decolonizing Global Mental Health: The Psychiatrization of the Majority World. Routledge: Abingdon. Moerman D (2002). Meaning, Medicine and the 'Placebo Effect'. Cambridge University Press: Cambridge.

Obeyesekere G (1985). Depression, Buddhism, and the work of culture in Sri Lanka. In Culture and Depression: Studies in the Anthropology and Cross-Cultural Psychiatry of Affect and Disorder (ed. A Kleinman and B Good), pp. 134-152. University of California Press: Berkeley.

Patel V (2014). Why mental health matters to global health. Transcultural Psychiatry 51, 777-789.

Patel V, Simon G, Chowdhary N, Kaaya S, Araya R (2009). Packages of care for depression in low- and middle-income countries. PLoS Medicine 6, e10000160. doi: 10.1371/journal. pmed.1000159.

Patel V, Boyce N, Collins PY, Saxena S, Horton R (2011). A renewed agenda for global mental health. Lancet 378, 14411442.

Porter R (2002). Madness: A Brief History. Oxford University Press: Oxford.

Raguram R, Venkateswaran A, Ramakrishna J, Weiss MG (2002). Traditional community resources for mental health: a report of temple healing from India. BMJ 325, 38-40.

Rasmussen K (2009). Sham electroconvulsive therapy studies in depressive illness: a review of the literature and consideration of the placebo phenomenon in electroconvulsive therapy practice. Journal of ECT 25, 54-59.
Read J, Bentall R (2010). The effectiveness of electroconvulsive therapy: a literature review. Epidemiologia e Psichiatria Sociale 19, 333-347.

Repper J, Perkins R (2003). Social Inclusion and Recovery: A Model for Mental Health Practice. Balliere Tindall: London.

Schweder R (2003). Why do Men Barbecue? Recipes for Cultural Psychology. Harvard University Press: Massachussetts.

Shukla A, Philip A, Zachariah A, Phadke A, Suneetha A, Davar B, CEHAT, Srinivasan C, Mankad D, Qadeer I, Kalathil J, Lalita K, Sajaya K, Jacob KS, Balimahabal K, Gupte M, Rao M, Salie M, Prakash P, Chatterjee P, Baru R, Melkote R, Shukla R, Galtonde R, Bisht R, Duggal R, Khanna R, Priva R, Srivatsan R, Timimi S, Sarojini NB, Sathyamala C, Ashtekar S, Fernando S, Tharu S, Shatrugna V (2012). Critical perspectives on the NIMH 'Grand Challenges to Mental Health'. Indian Journal of Medical Ethics 9, 292-293.

Stastny P, Lehmann P (2007). Alternatives Beyond Psychiatry. Peter Lehmann Publishing: Berlin.

Summerfield D (2008). How scientifically valid is the knowledge base of global mental health? BMJ 336, 992-994.

Summerfield D (2012). Afterword: against 'global mental health'. Transcultural Psychiatry 49, 519-530.

White R, Sashidharan SP (2014). Towards a more nuanced global mental health. British Journal of Psychiatry 204, 415-417. 